\title{
Ugi Four-component Reaction (U-4CR) Under Green Conditions Designed for Undergraduate Organic Chemistry Laboratories
}

\author{
Mariana Ingold, Lucia Colella, Rosina Dapueto, Gloria. V. López , Williams Porcal* \\ Department of Organic Chemistry, Faculty of Chemistry, University of the Republic, Montevideo, Uruguay \\ *Corresponding author
}

\begin{abstract}
Multicomponent reactions (MCRs) are a green strategy in which a collection of molecules with a great diversity are generated with a minimum of synthetic effort, time and by-products formation. The Ugi Multi-component reaction is a chemical reaction in which an aldehyde, an amine, a carboxylic acid and an isocyanide react to form a $\alpha$-bisamide. In this work, we use the Ugi reaction, as an example of MCRs, to approach organic chemistry undergraduate students to sustainable reactions. This reaction can be carried out under on-water or solvent-free conditions, both at room temperature as in combination with microwave irradiation or ultrasound. The advantages and limitations of the usage of Ugi reaction, under these conditions, in an organic chemistry laboratory course are discussed. In this context, we used different parameters to calculate how environmentally friendly the assayed conditions are. The Chemical Manufacturing Methods for the 21st Century Pharmaceutical Industries (CHEM21 project) were used with this objective. The present work could contribute to the teaching of ecofriendly synthetic strategies, demonstrating the scientific and academic benefits of green chemistry.
\end{abstract}

Keywords: green chemistry, solvent-free, on-water, microwave, Multicomponent Reaction, Ugi, Metrics Toolkit

Cite This Article: Mariana Ingold, Lucia Colella, Rosina Dapueto, Gloria. V. López, and Williams Porcal, "Ugi Four-component Reaction (U-4CR) Under Green Conditions Designed for Undergraduate Organic Chemistry Laboratories.” World Journal of Chemical Education, vol. 5, no. 5 (2017): 152-157. doi: 10.12691/wjce-5-5-2.

\section{Introduction}

The education of chemists is ever-evolving and requires keeping up with the latest discoveries, concepts, perspectives and techniques in the field [1,2]. Educating young scientists about use and benefits of sustainable methodologies could make a difference in their future careers as scientists and this could be critical to foster for a sustainable developing future. Since one of the greatest challenges for medicinal chemistry is to identify fast, safe and efficiently new drug candidates, it is essential that research groups use new methodologies that not only allow reaching these objectives but also in an environmentally friendly way $[3,4]$. In recent years, the development of green chemistry contributed to reduce chemical related impact on human health and environment [5]. There are many alternative or "greener" reaction techniques that improve substantially the product yield, saving energy and minimizing waste $[6,7,8]$. Reactions using water as solvent or under solvent-free conditions in combination with microwave or ultrasound assisted organic synthetic techniques, are some of these new sustainable methodologies in chemical synthesis [9]. The reduction of energy consumption is a very important goal concerning the energy savings and the climate change which has become a global environmental problem. The chemical industry has invested high resources to reduce energy demands making innovative changes in synthetic reaction conditions (lower temperatures, reducing steps).

Multicomponent reactions (MCRs) are one of the most promising synthetic strategies for generating collections of small molecules, since they offer greater possibilities for molecular diversity per step with a minimum of synthetic effort, time and formation of by-products [10,11]. MCR is defined as a reaction in which three or more compounds react in a single operation to form a single product that contains essentially all of the atoms of the starting materials. Ugi four-component reaction (U-4CR) is an example of the efficiency of this approach. Four components are involved in this reaction (aldehyde, amine, carboxylic acid and isocyanide) to give a bis-amide derivative and water (Scheme 1) [12,13].

In the last decade, several studies have been conducted to improve the yield, reduce the cost, the ecological impact, and the reactions times of MCRs [14,15]. In this context, young scientists need to acquire the ability to correctly design the greenest synthesis strategy during their training courses. Multivariate metrics, atom economy and environmental factors provide sufficient information to properly select a green process $[16,17]$. Although there are several lab proposals concerning multicomponent reactions $[18,19,20]$, the experiment described herein highlights Ugi reaction under on-water or solvent-free conditions, in combination with microwave irradiation or ultrasound, and discusses their advantages and limitations for use in an organic chemistry laboratory course. 
Therefore, students could develop the knowledge of selecting the greenest synthetic strategy by considering various environmental impact metrics when using different synthetic conditions. Students could initially select the greenest synthesis by quantifying the environmental impact of all reagents, solvents and energy involved in each synthetic condition. To meet this objective, in the present article we have used a new software tool called "CHEM21 Metrics Toolkit" [21].

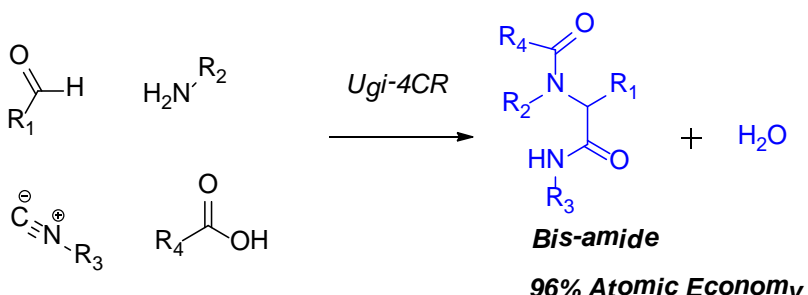

Scheme 1. Ugi multicomponent reaction

\section{Materials and Methods}

Chemicals were purchased from Sigma (St. Louis, MO) or Aldrich (Milwaukee, WI) at the highest purity available. ${ }^{1} \mathrm{H}$ NMR and ${ }^{13} \mathrm{C}$ NMR spectra were recorded on a Bruker DPX-400 instrument, with $\mathrm{CDCl}_{3}$ as solvent and tetramethylsilane as the internal reference. Electron impact (EI) mass spectra were obtained at $70 \mathrm{eV}$ on a Shimadzu GC-MS QP 1100 EX. TLC was carried out on Alugram ${ }^{\circledR}$ Sil G/UV254 or Aluminum oxide on polyester plates. Column chromatography (CC) was carried out on silica gel (Merck, 60-230 mesh). Reactions were performed using a monomode CEM Discover microwave reactor and Ultrasounds Daihan Labtech CO. Model LUC405, working at $350 \mathrm{~W}$ and $50 \mathrm{kHz}$ (Ultrasonic Cleaning Bath).

\subsection{Synthetic Procedures for Ugi Reaction}

Method A (room temperature). Benzaldehyde (2 mmol, $0.21 \mathrm{~g}$ ), aniline ( $2 \mathrm{mmol}, 0.18 \mathrm{~mL}$ ), benzoic acid ( $2 \mathrm{mmol}$, $0.25 \mathrm{~g}$ ), and tert-butyl isocyanide ( $2 \mathrm{mmol}, 0.17 \mathrm{~g}$ ) were placed in a round bottom flask containing $6.6 \mathrm{~mL}$ of water (or without solvent) in said order. The reaction mixture is left with magnetic stirring for the time corresponding at room temperature. Subsequently the reaction mixture is diluted with saturated $\mathrm{NaHCO}_{3}$ solution $(15.0 \mathrm{~mL})$ and extracted with ethyl acetate $(2 \times 20 \mathrm{~mL})$, and then the organic layer is washed with $10 \% \mathrm{HCl}$ and finally washed with saturated $\mathrm{NaCl}$ solution. Dry over anhydrous $\mathrm{Na}_{2} \mathrm{SO}_{4}$, filter and evaporate the solvent under reduced pressure. The crude obtained is purified by CC (flash $\mathrm{SiO}_{2}$, Heptane: Ethyl acetate (7: 3)) to give a white solid.

Method $B$ (microwave-assisted). A glass tube was charged sequentially with benzaldehyde (2 mmol, $0.21 \mathrm{~g})$, aniline ( $2 \mathrm{mmol}, 0.18 \mathrm{~mL}$ ), benzoic acid ( $2 \mathrm{mmol}, 0.25 \mathrm{~g}$ ), and tert-butyl isocyanide ( $2 \mathrm{mmol}, 0.17 \mathrm{~g}$ ), under on-water condition $(6.6 \mathrm{~mL})$, solvent free condition or EtOH $(6.6 \mathrm{~mL})$. The sealed test tube was heated $30 \mathrm{~min}$ at $60^{\circ} \mathrm{C}$ by microwave irradiation. The vial was allowed to cool, and the crude reaction mixture was treated with aqueous-saturated $\mathrm{NaHCO}_{3}$ solution and extracted with ethyl acetate. The organic layer was washed with brine, dried with $\mathrm{Na}_{2} \mathrm{SO}_{4}$ and evaporated under reduced pressure. The residue was purified by flash column chromatography $\left(\mathrm{SiO}_{2}\right.$, heptane/ ethyl acetate).

Method C (ultrasound-assisted). Benzaldehyde (2 mmol, $0.21 \mathrm{~g}$ ), aniline ( $2 \mathrm{mmol}, 0.18 \mathrm{~mL}$ ), benzoic acid (2 mmol, $0.25 \mathrm{~g}$ ), and tert-butyl isocyanide ( $2 \mathrm{mmol}, 0.17 \mathrm{~g}$ ) were sequentially introduced into a round bottom flask containing $6.6 \mathrm{~mL}$ of water (or without solvent); then it was placed inside an ultrasound apparatus. It was exposed for $30 \mathrm{~min}$ at $350 \mathrm{~W}$ and $50 \mathrm{~Hz}$. The reaction mixture was then allowed to cool, treated with $\mathrm{NaHCO}_{3}$ saturated solution and extracted with ethyl acetate. The combined organic layers were washed with brine and dried with $\mathrm{Na}_{2} \mathrm{SO}_{4}$, filtered and the solvent evaporated under reduced pressure. Finally, purification by flash column chromatography $\left(\mathrm{SiO}_{2}\right.$, heptane/EtOAc) yielding desired product.

White solid, m.p. 68-72 ${ }^{\circ} \mathrm{C} .{ }^{1} \mathrm{H}-\mathrm{NMR}\left(\mathrm{CDCl}_{3}\right) \delta$ : 7.357.24 (m, 7H), 7.20-7.12 (m, 3H), 7.02 (s, 5H), 6.12 (s, 1H), $5.82(\mathrm{~s}, 1 \mathrm{H}), 1.40(\mathrm{~s}, 9 \mathrm{H}) .{ }^{13} \mathrm{C}-\mathrm{NMR}\left(\mathrm{CDCl}_{3}\right) \delta$ : $171.14,168.71,141.41,136.10,134.99,130.18,130.05$, $129.45,128.57,128.45,128.36,128.31,127.61,127.04$, 67.22, 51.68, 28.69.

\section{Results and Discussion}

One-pot MCRs are convergent reactions with high atom efficiency, and higher yields in comparison to a similar multistep reaction [11]. MCRs are powerful tools for organic chemistry, and among them, the Ugi reaction provides remarkable improvement in many fields of organic chemistry such as peptide chemistry, medicinal chemistry and combinatorial chemistry [12]. Ugi reaction has become one of the most investigated transformations during the past decade. The classical Ugi reaction is carried out in common solvents, such as dichloromethane and methanol under stirring at room temperature for several hours or days. Sustainable solvents are one of the most active areas of Green Chemistry research [22]. They represent an important challenge for Green Chemistry because they often account for the vast majority of mass wasted in syntheses and processes, and account for most of the industrial waste $[23,24]$. Therefore, the ideal situation would be to not use any solvent.

Considering the first Principle of the Green Chemistry, unused energy may also be considered as a waste. In this sense, the design of chemical reactions that do not require intensive energy is highly desirable. Increasing the energy efficiency of a chemical system could be part of the solution. The use of microwave irradiation or ultrasound as an efficiently energy source is a step forward in this direction, which can offer many advantages such as high yields, short reaction times and cleaner reactions $[25,26,27,28]$. In order to further comply with Green Chemistry, an alternative green solvent like water, or solvent-free conditions, and microwave irradiation or ultrasound, as more efficiently energy sources, were used in an Ugi multicomponent reaction.

In this experiment, the Ugi-4CR was carried out under different green conditions using benzaldehyde, aniline, benzoic acid and tert-butyl isocyanide as a model of 
chemical reactivity (Table 1). Particularly, all reagents were chosen for its low solubility in water, in order to highlight the condition of on-water catalysis in organic reactions.[29] The proposed mechanism of the Ugi reaction, initially involves protonation of the imine by a weak acid (e.g. a carboxylic acid) followed by nucleophilic addition of the isocyanide to the iminium ion (Scheme 2) [30]. The resulting nitrilium ion is subsequently attacked by the conjugate base of the weak acid (e.g. a carboxylate), which only needs to be a weak nucleophile. In this context, hydrogen-bound present in the organic-water interface could promote transition states and the formation of the different reaction intermediates [31].

As shown in Table 1 (Entry 1), when the reaction was carried out in the presence of water (on-water condition), Ugi product was obtained in high yield at room temperature in only 3h. When on-water Ugi-4CR was carried out using microwave irradiation (MW) in a closed vessel at $60^{\circ} \mathrm{C}$ or ultrasound (US), moderate yields were obtained (57 and 51\%, respectively) in shorter times (Table 1, entries 2 and 3). Ugi reaction usually requires high concentrations of reactants $(0.5-2 \mathrm{M})$, which are rarely achieved in aqueous solutions. Considering this fact and the fact that auxiliary substances (e.g., solvents) should be made unnecessary wherever possible (fifth principle of green chemistry), we planned to carry out a study in solvent-free conditions. Reactants, under neat conditions, stirred at room temperature for three or five hours, rendered the desired product with 65 and $74 \%$ yield, respectively (Table 1, entries 4 and 5). In order to reduce reaction times and improve yields, we tested the effects of microwaves and ultrasound, and compared the results.
When microwave radiation was used as heating source, the Ugi product was obtained in about $80 \%$ yield and ten times faster than at room temperature (Entry 6, Table 1). Yields obtained with ultrasound were comparable to those obtained by microwave, both at 0.5 and $1 \mathrm{~h}$ of reaction (Table 1, entries 7 and 8). The reaction was also carried out in a green organic solvent, $\mathrm{EtOH}$, under microwave radiation, (Table 1 , entry 9). The desired product was obtained in $69 \%$ yield, rendering better than when water was used but worsen than the solvent free condition.

Analyzing the results under the reaction conditions tested, it should be pointed out that similar yields were obtained at room temperature in both, aqueous medium and solvent-free conditions (71 and 65\%, respectively). As shown in Table 1, best yields are obtained when the reaction is conducted without solvent using both microwave and ultrasound irradiation. Considering that in all conditions tested the crude reaction was obtained as a pasty mass, and that pure product has a low melting point (mp $68-72^{\circ} \mathrm{C}$ ), it was not possible to obtain pure product by crystallization. Therefore, it was purified by a shortcolumn chromatography, minimizing the amount of mobile phase used.

Then, through the analysis of different reaction parameters, students can measure, compare and evaluate how green are each of the assayed conditions. The classical metric used by chemists is yield, followed by percentage of conversion and reaction selectivity. But, on the light of the 12 principles of green chemistry, in order to evaluate how green a procedure is, other metrics must be consider. To meet this objective we have used a new software tool called "CHEM21 Metrics Toolkit" [21].

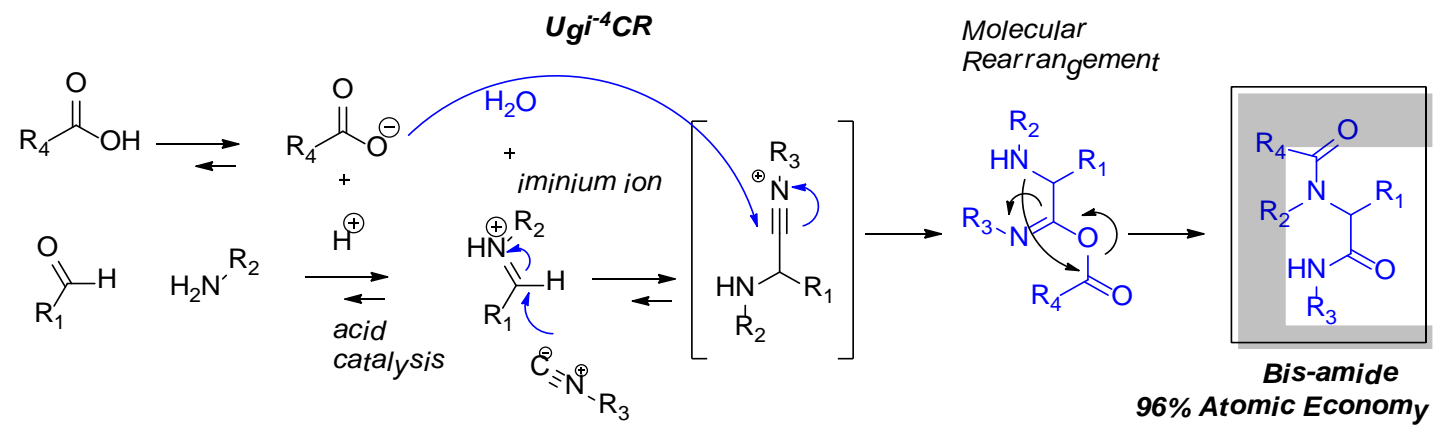

Scheme 2. Proposed mechanism of the Ugi multicomponent reaction

Table 1. Green experimental conditions tested for the Ugi reaction

\begin{tabular}{|c|c|c|c|}
\hline & Green cor & $\mathrm{lct}$ & \\
\hline Entry & Reaction conditions & Time (h) & Yield (\%) \\
\hline 1 & Water, rt & 3 & 71 \\
\hline 2 & Water, MW $\left(60^{\circ} \mathrm{C}\right)$ & 0.5 & 57 \\
\hline 3 & Water, US & 0.5 & 51 \\
\hline 4 & solvent-free, $\mathrm{rt}$ & 3 & 65 \\
\hline 5 & solvent-free, $\mathrm{rt}$ & 5 & 74 \\
\hline 6 & solvent-free, $\mathrm{MW}\left(60^{\circ} \mathrm{C}\right)$ & 0.5 & 78 \\
\hline 7 & solvent-free, US & 0.5 & 75 \\
\hline 8 & solvent-free, US & 1 & 82 \\
\hline 9 & $\mathrm{EtOH}, \mathrm{MW}\left(60^{\circ} \mathrm{C}\right)$ & 0.5 & 69 \\
\hline
\end{tabular}


Table 2. Conditions tested in the Ugi reaction and parameters analyzed according to the CHEM21 metrics toolkit [21]

\begin{tabular}{|c|c|c|c|c|c|c|c|c|c|c|c|c|}
\hline \multirow[t]{2}{*}{ Entry } & \multicolumn{4}{|c|}{ Zero pass } & \multicolumn{8}{|c|}{ First pass } \\
\hline & AE (\%) & RME (\%) & $\mathrm{OE}$ & $\mathrm{H} \& \mathrm{~S}$ & PMI & Solvents & $\begin{array}{l}\text { Catalyst// } \\
\text { enzyme }\end{array}$ & $\begin{array}{c}\text { Critical } \\
\text { elements }\end{array}$ & Energy & Work-up ${ }^{\text {a }}$ & Batch/flow & $\mathrm{H} \& \mathrm{~S}$ \\
\hline 1 & 96 & 66 & 70 & (-) & 94 & (-) & (;) & ()) & (-) & 5 & 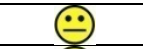 & (-) \\
\hline 2 & 96 & 50 & 52 & (:) & 115 & (:) & (:) & (;) & (;) & & 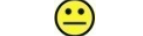 & (;) \\
\hline 3 & 96 & 49 & 51 & (-) & 118 & (:) & (:) & (:) & (-) & ) & $\ominus$ & (;) \\
\hline 4 & 96 & 60 & 63 & (;) & 78 & (:) & (;) & (;) & (;) & 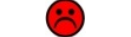 & $\ominus$ & (;) \\
\hline 5 & 96 & 65 & 68 & (ت) & 67 & (ت) & (ن) & (ت) & (ت) & ) & (-) & (ت) \\
\hline 6 & 96 & 70 & 73 & (;) & 62 & (:) & (:) & (;) & (;) & ) & 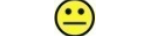 & (:) \\
\hline 7 & 96 & 66 & 69 & (ن) & 66 & (ن) & (ن) & (ن) & (ن) & ) & $\dddot{-}$ & (ن) \\
\hline 8 & 96 & 72 & 76 & (:) & 60 & (ت) & (:) & (-) & (:) & 2 & 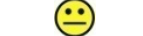 & (:) \\
\hline 9 & 96 & 66 & 69 & (ت) & 98 & (ت) & (ت) & (ت) & (ت) & 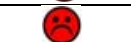 & $\ddot{\theta}$ & (ت) \\
\hline
\end{tabular}

The toolkit is split into a number of passes or levels with increasing complexity as the synthesis moves from discovery, through scale-up, towards commercialization: Zero, First, Second and Third Pass. Zero Pass and First Pass were designed for use in laboratory research at the discovery stage, where most of the reactions are carried out on a small scale, and therefore they will be consider herein. Zero Pass concentrates on identifying issues surrounding the use of highly hazardous substances as well as an initial appraisal of the efficiency of the route. Then, processes or reaction conditions that have shown potential in the Zero Pass, move to the evaluation in the First Pass. Hence, a more in-depth investigation of the green credentials of a reaction including comparing different routes to the same target compound is evaluated. In Table 2, Ugi reaction conditions and parameters analyzed according to the CHEM21 metrics toolkit, are summarized. In our experiment, AE always corresponds to $96 \%$, since a minimum percentage of water is generated as a byproduct. With respect to RME and OE, in most cases is between 50 and $75 \%$, therefore in practice, our product of interest is obtained in good amount of mass. Regarding to the health and safety parameter (H\&S, Table 2), only solvents and reagents with indications of severe hazard should be avoided in the Zero Pass. For that reason, to all studied conditions a green smiling emoticon was initially assigned. In summary, Zero Pass parameters shown that solvent-free Ugi reaction at room temperature, and microwave or ultrasound heating are the best conditions for an efficient and safe process. Next, since reaction conditions assayed show potential at Zero Pass, one can go ahead to First Pass where others metrics allow further investigation of the green credentials of a reaction. AE and RME only provided information about the efficiency of the reaction in terms of the reactants. Mass intensity (MI, single step) or process mass intensity (PMI, entire process) is a valuable metric that captures all mass based inputs, such as solvents, catalysts, reagents, work up, etc. PMI metric represents the ratio of the total mass in the process and the mass of product. Among the studied conditions, the best PMI values were obtained when Ugi reaction was carried out in the absence of solvent, both under microwave or ultrasound irradiation (Table 2, entries 6 and 8). This result is even clearer if we consider that the solvent typically constitute at least half the mass intensity of a synthetic process. In this context, green smiling emoticons were included for all conditions studied (solvents metric) since water or solvent free conditions were used. Regarding to other metrics that can be evaluated, such as the use of catalysts, critical elements and energy, this reaction takes place under mild conditions (temperature is maintained between 0 to $70^{\circ} \mathrm{C}$ ), without catalysts and all elements used are widely accessible. Therefore, green smiling emoticons were awarded. Besides, since the reaction is carried out in batch conditions, yellow serious emoticons were given.

However, considering that work-up involved the use of solvent for product extraction and subsequent column chromatography, its industrial application would be subject of improvement regarding the purification process of the final product; therefore, red sad emoticons were given.

\section{Conclusions}

The environmental impact due to chemical processes is clear and unquestionable. Chemistry students must become aware of the impact of their work from the early stages of their training so that in their future, at industry or academia, they could promote the development of sustainable processes and environmentally friendly methodologies. For that reason, it is necessary to give students the skills, tools and techniques to make adequate decisions considering green chemistry principles. The laboratory experiment proposed herein for undergraduate students of organic chemistry, involves the use of a multicomponent reaction performed under friendly environmental conditions. Improvement of the efficiency, minimizing the production of waste and the use of energy, were the main objectives. In addition to this, we introduced the use of metrics that can allow students to evaluate the impact of each reaction condition and thus judge which one is "greener".

\section{Acknowledgements}

We are grateful to the National Agency for Research and Innovation (ANII), Development Program of the 
Basic Sciences (PEDECIBA-Química) and University of the Republic of Uruguay (UdelaR) for financial support.

\section{References}

[1] Anastas, P.T.; Beach, E.S. Green Chemistry Education. Changing the Course of Chemistry. ACS Symposium Series; American Chemical Society: Washington, DC, 2009.

[2] Moore, J.W. "What's the Future of Chemistry?" Chem. Edu. Inter., 1. 8-10. 2000.

[3] Clark, J.H. "Green chemistry: challenges and opportunities." Green. Chem., 1. 1-8. 1999.

[4] Gaich, T.; Baran, P.S. J. “Aiming for the Ideal Synthesis.” J. Org. Chem. 75. 4657-4673. 2010.

[5] Anastas, P. T.; Warner, J. C. Green Chemistry: Theory and Practice; Oxford University Press: New York, 1998.

[6] Eissen, M.; Metzger, J.O. "Environmental Performance Metrics for Daily Use in Synthetic Chemistry.” Chem. Eur. J., 8. 35813585. 2002.

[7] Linthorst, J. A. "An overview: origins and development of green chemistry” Found Chem., 12. 55-68. 2010.

[8] Anastas, P., Eghbali, N. "Green Chemistry: Principles and Practice." Chem. Soc. Rev., 39. 301-312. 2010.

[9] Zhang, W.; Cue JR, BW. Green Techniques for organic synthesis and medicinal chemistry. John Wiley \& Sons, Ltd. 2012.

[10] Cioc, R.C.; Ruijter, E.; Orru, R.V.A. "Multicomponent Reactions: Advanced Tools for Sustainable Organic Synthesis." Green. Chem. 16. 2958-2975. 2014.

[11] Ruijter, E.; Scheffelaar, R.; Orru, R.V.A. "Multicomponent reaction design in the quest for molecular complexity and diversity.” Angew. Chem. Int. Ed., 50. 6234-6246. 2011.

[12] Domling, A.; Ugi, I. "Multicomponent reaction with isocyanides." Angew. Chem. Int. Ed., 39. 3168-3210. 2000.

[13] Pirrung, M.; Das Sarma, K. "Aqueous medium effects on multi-component reactions.” Tetrahedron, 61. 11456-11472. 2005.

[14] Hulme, C.; Chappeta, S.; Dietrich, J. "A simple, cheap alternative to 'designer convertible isonitriles' expedited with microwaves." Tetrahedron. Lett., 50. 4054-4057. 2009.

[15] Ingold, M.; López, G.V.; Porcal, W. "Green Conditions for Passerini Three-Component Synthesis of Tocopherol Analogues" ACS Sust Chem Eng, 2. 1093-1097. 2014.

[16] Mercer, S.M.; Andraos, J.; Jessop, P.G. "Choosing the Greenest Synthesis: A Multivariate Metric Green Chemistry Exercise.” J. Chem. Educ., 89. 215-220. 2012.
[17] Jiménez-González, C.; Constable, D.J.C.; Ponder, C.S. "Evaluating the "Greenness" of chemical processes and products in the pharmaceutical industry-a green metrics primer." Chem. Soc. Rev., 41. 1485-1498. 2012.

[18] Bossio, R.; Marcaccini, S.; Pepino, R. "Multicomponent Reactions. A Convenient Undergraduate Organic Chemistry Experiment." $J$. Chem. Educ., 77. 382-384. 2000

[19] Candeias, N.R.; Paterna, R.; Cal, P.M.S.D.; Góis, P.M.P. A Sustainable Protocol for the Aqueous Multicomponent Petasis Borono-Mannich Reaction. J. Chem. Educ. 2012, 89, 799-802.

[20] Damkaci, F.; Szymaniak, A.; "Multicomponent Heterocyclic Chemistry for Undergraduate Organic Laboratory: Biginelli Reaction with Multiple Unknowns” J. Chem. Educ., 91. 943-945. 2014.

[21] McElroy, C.R.; Constantinou, A.; Jones L.C.; Summerton, L.; Clark, J.H. "Towards a holistic approach to metrics for the 21st century pharmaceutical industry.” Green. Chem., 17. 3111-3121. 2015.

[22] Li, Chao-Jun; Trost, B. M. "Green chemistry for chemical synthesis.” Proc. Nat. Acad. Sci., 105. 13197-13202. 2008.

[23] Capello, C.; Fischer, U.; Hungerbuhler, K. "What is a green solvent? A comprehensive framework for the environmental assessment of solvents." Green. Chem., 9. 927-934. 2007.

[24] Jessop, P.G. "Searching for green solvents.” Green. Chem., 13. 1391-1398. 2011.

[25] Varma, R.S. "Solvent-free organic syntheses using supported reagents and microwave irradiation." Green. Chem., 1. 43-55. 1999.

[26] Hayes, B.L. Microwave Synthesis. Chemistry at the Speed of Light. CEM Publishing 2002.

[27] Cui, C.; Zhu, C.; Du, X.J.; Wang, Z.P.; Li, Z.M.; Zhao, W.G. "Ultrasound-promoted sterically congested Passerini reactions under solvent-free conditions.” Green. Chem., 14. 3157-3163. 2012.

[28] Chen, D.; Sharma, S.K.; Mudhoo, A. Handbook on Applications of Ultrasound. Sonochemistry for Sustainability. CRC Press. Taylor \& Francis Group 2012.

[29] Narayan, S.; Muldoon, J.; Finn, M.G.; Fokin, V.V.; Kolb, H.C.; Sharpless, K.B. "On water: unique reactivity of organic compounds in aqueous suspension.” Angew. Chem. Int. Ed., 44. 3275-3279. 2005.

[30] Herrera, R.P.; Marqués-López, E. Multicomponent reactions. Concept and applications for design and synthesis. John Wiley \& Sons, Inc 2015.

[31] Jung, Y. S.; Marcus, R. A. "On the Theory of Organic Catalysis “on Water”." J. Am. Chem. Soc., 129. 5492-5502. 2007. 